\title{
Optimization of the Arc Spraying Process Parameters of the Fe-Base Mn-Si-Cr-Mo-Ni Coatings for the Best Wear Performance
}

\author{
Justinas GARGASAS ${ }^{1}$ *, Algirdas Vaclovas VALIULIS ${ }^{1}$, Irmantas GEDZEVIČIUS ${ }^{1}$, \\ Šarūnas MIKALIŪNAS ${ }^{1}$, Saulius NAGURNAS ${ }^{1}$, Hanna POKHMURSKA ${ }^{2}$
}

\author{
${ }^{1}$ Department of Materials Science and Welding, Faculty of Mechanics, Vilnius Gediminas Technical University, Sauletekio \\ al. 11 LT-10223, Vilnius \\ ${ }^{2}$ Institute of Materials Science and Engineering, Chemnitz University of Technology, Reichenhainer Straße 39, DE-09126, \\ Chemnitz, Germany
}

cross $^{\text {ref }}$ http://dx.doi.org/10.5755/j01.ms.22.1.7339

Received 16 June 2014; accepted 06 March 2015

\begin{abstract}
In this paper, the use of $\mathrm{Fe}-$ base $\mathrm{Mn}-\mathrm{Si}-\mathrm{Cr}-\mathrm{Mo}-\mathrm{Ni}$ and $\mathrm{Fe}-$ base $\mathrm{Mn}-\mathrm{Si}-\mathrm{Cr}$ wires for thermal arc spraying is presented. For this purpose the mechanical and physical properties of coatings were evaluated. The quality of the coating's was dependent on the selected equipment, spray materials, technological parameters of the spray and spray technology. The aim was to qualify and optimize the parameters for spray coating to get the best coatings properties with good tribological properties. All coatings were deposited on mild steel S235JR substrates. Two experimental cored wires of unique chemical composition - STEIN-MESYFIL $932 \mathrm{~V}$ and STEIN-MESYFIL $954 \mathrm{~V}$ - were used for thermal arc spraying. The wires of $1.6 \mathrm{~mm}$ diameter were used for the surfacing material. Hardness, porosity and oxide measurements were used to verify the spray parameters and analyze the coatings. Rubber wheel test, which is based on the standard ASTM G65, was used. Dry-sand, rubber-wheel procedure according ASTM G65 was used to investigate low stress abrasion, whereas for high stress abrasion investigations a rubber wheel was used. This experiment was carried out by changing the speed of disc friction, travel distance and measuring the mass loss of surface friction. Miller Test according to ASTM G75-95 Standard was carried out in experiment with friction. The samples were immersed in water with corundum and polished with $22 \mathrm{~N}$ load, for 8 hours. Furthermore a correlation was performed between the spraying current and voltage parameter. The coatings' cross sections were examined using scanning electron microscope (SEM) and optical microscopy.

The influence of the composite components of the coatings' microstructure, such as porosity, microhardness, oxide inclusions, on the tribological properties of thermal sprayed coatings is discussed in this paper.

Keywords: cored wires, $\mathrm{Fe}$ - based, thermal arc spray, Miller test, rubber wheel abrasion test.
\end{abstract}

\section{INTRODUCTION}

$\mathrm{Fe}$ - base $\mathrm{Mn}-\mathrm{Si}-\mathrm{Cr}-\mathrm{Mo}-\mathrm{Ni}$ and $\mathrm{Fe}$ - base $\mathrm{Mn}-\mathrm{Si}-\mathrm{Cr}$ wires are used as the materials in the thermal arc spraying for the wear protection of tools, machine parts, hydraulic pistons, shafts and journal bearings, agricultural machinery and others. Electric arc is used in an electric arc spray process (also known as the wire arc process). Where two consumable wire electrodes are connected to a high-voltage direct-current (DC) power source and brought together in the gun, establishing the arc between them that melts the tips of the wires. The molten metal is then atomized and propelled toward the substrate by a stream of air. The process is energy efficient because all of the input energy is used to melt the metal. Spray rates are driven primarily by operating current and vary as a function of both melting point and conductivity. Electric arc spraying also can be carried out using inert gases or in a controlled atmosphere chamber $[1,2]$. Temperatures within the arc rise up to $6500{ }^{\circ} \mathrm{C}$ [3]. High temperature at the wire ends can cause a burning loss of alloying elements in the spray materials. For elements such as silicon or manganese, loss can rise to $40 \%$, for other elements, e.g. carbon, even up to $60 \%$ [3]. Adapted alloyed bulk or filled wires are therefore necessary.
Thermal spray metallic coatings are highly capable of improving the superficial wear resistance of industrial components. Spray filler materials and the specific processes and parameters predominantly influence the characteristics and hence the properties of the sprayed coatings. Spray coatings consist of single, flattened particles of different size. The pores, gas inclusions, unmelted wire material and other contaminations, cracks of various sizes and interface delamination are found in the thermal sprayed coatings (it depends on the chosen spraying conditions and materials). It is typical for the coatings of such type. [4-6]. They may also contain oxide layers and inclusions between the splats too. The oxide inclusions form as a result of oxidation of molten metal droplets while in-flight. The oxide layers between the splats are probably the result of both surface oxidation of the molten metal droplets in-flight, and continued oxidation of the splats on the surface as they solidify.

The process and feedstock variables jointly influence the chemical and mechanical coating's properties like chemical composition, microstructure, coating adhesion and toughness. Therefore, the resulting friction and wear behavior of arc sprayed wear protective coatings are likewise influenced. In addition, the inhomogeneous

\footnotetext{
* Corresponding author. Tel.: +370-616-51275; fax: (8-5) 2700112.

E-mail address: justinas.gargasas@vgtu.lt (J. Gargasas)
} 
microstructures of spray coatings strongly influence the coatings' wear behaviors, too.

Spray materials and the spray process parameters mainly affect the characteristics and the properties of the sprayed coatings. A large variety of thermal spray coatings is tested concerning their capability to with dry abrasive wear [7]. As a result, discussion of the wear behavior and pattern of thermally sprayed coatings is much more complex than for homogeneous bulk materials. Therefore wear of spray coatings can be traced back to splat delamination due to oxide lamellas between the coating-forming splats [8].

This work is focused on elevated new experimental thermal arc spray $\mathrm{Fe}$ - base cored wires and their coatings. The research of optimization thermal arc spraying process gave opportunity to understand dependence between the coating's structure and its microhardness and tribological properties. The tribological behavior of these coatings was investigated by Miller, carrying out the rubber/wheel abrasion test. The coatings were evaluated for microhardness by cross-sectional microstructure analysis with scanning electron microscope. The results from these analyses and associated interpretations are discussed below.

\section{EXPERIMENT PROCEDURES}

\subsection{Coating material}

The used coating materials were two experimental cored wires of unique chemical composition - STEINMESYFIL $932 \mathrm{~V}$ and STEIN-MESYFIL $954 \mathrm{~V}$. The diameter of the wires was $1.6 \mathrm{~mm}$. Those electro arc wires are used for increasing the abrasive wear resistance of products to various abrasive minerals, including earth. The chemical composition of the given feedstock wires is given in Table 1. All coatings were deposited on mild steel S235JR substrates to a thickness of $695 \mu \mathrm{m}$ and $940 \mu \mathrm{m}$. Samples of dimension of $150 \mathrm{~mm} \times 25 \mathrm{~mm}$ were cut from the larger plates.

Table 1. Chemical composition of the wires used as arc spray feedstock

\begin{tabular}{|c|c|c|c|c|c|c|}
\hline \multirow{2}{*}{ Feedstock wire } & \multicolumn{6}{|c|}{ Chemical composition (wt.\%) Fe balance } \\
\cline { 2 - 7 } & $\mathrm{C}$ & $\mathrm{Mn}$ & $\mathrm{Si}$ & $\mathrm{Cr}$ & $\mathrm{Mo}$ & $\mathrm{Ni}$ \\
\hline $\begin{array}{c}\text { Stein-Mesyfil } \\
\text { 932V }\end{array}$ & 0.5 & 1.1 & 0.3 & 0.3 & 4.8 & 1.5 \\
\hline $\begin{array}{c}\text { Stein-Mesyfil } \\
\text { 954V }\end{array}$ & 1.3 & 0.8 & 1.4 & 6.5 & - & - \\
\hline
\end{tabular}

\subsection{Equipment and parameters of thermal spraying}

The experiments were carried out using a stand of Castolin - Eutectic EuTronic arc spraying system and a Kemppi Pro 5200 welding machine used consisted of a power supply with a control unit and the arc spraying gun. The Kemppi welding machine with synergic adjustment was used to ensure good spraying stability and correlation of spraying parameters. Spray distance was between 150 and $160 \mathrm{~mm}$. The processing parameters are shown in Table 2. Voltage was adjusted during the spraying process. The minimal voltage was selected to ensure a stable spraying process. The spraying voltage depends on sprayed materials also. Some sets of voltage values are different. The spray gas in each case was dry compressed air (pressure 5 bar).
Table 2. Spray process current and voltage variations

\begin{tabular}{|c|c|c|c|}
\hline Feedstock & Experiment & Current, A & Voltage, V \\
\hline \multirow{2}{*}{$\begin{array}{c}\text { Stein - Mesyfil } \\
\text { 932V }\end{array}$} & 1 & 320 & 31 \\
\cline { 2 - 4 } & 2 & 350 & 36 \\
\hline \multirow{2}{*}{$\begin{array}{c}\text { Stein - Mesyfil } \\
\text { 954V }\end{array}$} & 3 & 380 & 38 \\
\cline { 2 - 4 } & 2 & 320 & 30 \\
\cline { 2 - 4 } & 3 & 350 & 36 \\
\hline
\end{tabular}

\subsection{Study of microhardness and microstructure}

Vickers microhardness tests were performed to identify which coatings have the best mechanical properties. HV 0.1 and HV 0.3 microhardness tests were carried out. The microhardness was measured at the cross sections. The microstructure of the coatings was measured on the cross sections (grinded and polished by automatic Leco grinding and polishing equipment) with optical microscope and SEM microscope. Optical image analysis with Scion Image program was carried out on cross sections to evaluate porosity and oxide levels in the coatings.

\subsection{Wear testing}

Wear tests were performed with a standardized ASTM G65 dry - sand rubber - wheel tester (3-body abrasion), which is shown in Fig. 1.

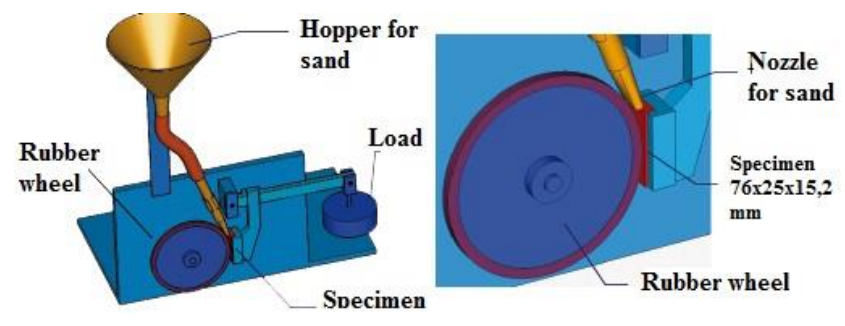

Fig. 1. Scheme of dry-sand rubber wheel

The rubber wheel is in contact with a specimen under an applied load. A flow of sand particles is directed to the gap between a rotating rubber wheel and the specimen. The sand particles scratch the surface of the specimen under the applied load at a sliding speed of $w \times R$, where $w$ is the angular speed of the rubber wheel and $R$ is its radius. In the study silica sand with the average grain size of $300 \mu \mathrm{m}$ was used, which was fed at a flow rate of 300 to $400 \mathrm{~g} / \mathrm{min}$ $[5,9,10]$ as recommended by ASTM G65 for the dry sand rubber wheel abrasion test. The specimens for the wear test had dimension of $40 \mathrm{~mm} \times 25 \mathrm{~mm} \times 3 \mathrm{~mm}$. Wear loss of a specimen was evaluated by measuring the mass loss of the specimen after 1000 wheel revolutions corresponding to the sliding distance of $718 \mathrm{~m}$ wear track length. The weight losses were converted to the volume loss by putting in comparison the measured coatings and substrate mass before and after the experiment. Specimens were tested three times according to each standard to gain an average mass and respectively an average volume loss. The volumetric wear was calculated according to the weight loss and the density of the coatings [5]. The volume loss is adjusted after the diameter of rubber wheel decreases because of friction.

The "adjusted volume loss" value takes this into account and indicates the actual abrasion rate that would be 
protected by a $228.6 \mathrm{~mm}$ diameter wheel. The adjusted volume loss (AVL) is calculated using a formula:

$$
A V L=\text { volume loss } \times \frac{228.6 \mathrm{~mm}}{\text { wheel diameter after use }} .
$$

Another wear test was performed using Miller test according to ASTM G75 - 95 standard. The Miller test machine is shown in Fig. 2. The relative effect of slurry abrasivity in the Miller Number is determined by using the measured mass loss of a standard-shaped metal block, driven in a reciprocating motion by a rotating crank, riding in the bottom of a tray containing the slurry. The samples were immersed in water with corundum and polished with $22 \mathrm{~N}$ load. The drive mechanism provides a horizontal reciprocating harmonic motion to the block arm of $200 \mathrm{~mm}$ travel. This test run in $2 \mathrm{~h}$ increments, ends after 8 hours and gives essentially equivalent results. The direction of the movement during the test was from the rotating crank side shown in Fig. 2 [5] to the right side and back. The Miller number is an index of the relative abrasivity of slurries. Its primary purpose is to rank the abrasivity of slurries in terms of the wear of a standard reference material. The wear damage on the standard wear block is worse as the Miller number gets higher [11]. The Miller Number is described as index related to the rate at which the wear block loss mass can be calculated using a formula (2). This becomes the slope of the line tangent to the curve at $2 \mathrm{~h}$ in each experiment.

mass - loss - rate, $\frac{\mathrm{mg}}{\mathrm{h}}=A \times B \times t^{(B-1)}$.

The values of $A$ and $B$ are calculated for the curve closely matching the test data curve.

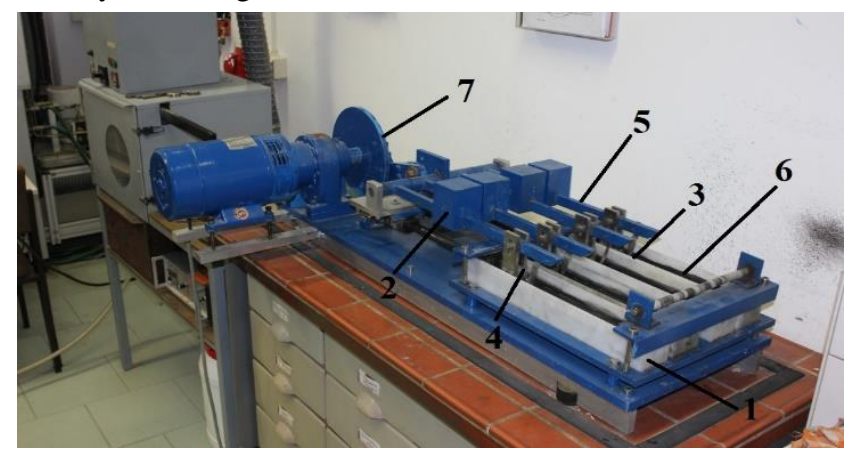

Fig. 2. Used Miller Test device according to ASTM G75 - 95 standard (1-moulded plastic tray, 2-dead weight, 3 -wear block with coating, 4 -adjustable plastic wear black holder, 5-pivoted reciprocating arm, 6-sand slurry, 7 - rotating crank)

\section{RESULTS AND DISCUSSION}

The coatings' microhardness (the mark of the microhardness tester is given in Fig. 3.) strongly depends on the coatings' chemical compositions (see Table 2) and spraying parameters (see Table 1) and is decreased by about $16 \%$ in the STEIN-MESYFIL $932 \mathrm{~V}$ coatings in comparison to the STEIN-MESYFIL $954 \mathrm{~V}$ coatings. The microhardness of sprayed coatings are from $714 \mathrm{HV}$ to $836 \mathrm{HV}$ using $100 \mathrm{~g}$ load and from $494 \mathrm{HV}$ to $604 \mathrm{HV}$ using $300 \mathrm{~g}$ load. The results are given in Table 3 . The microhardness depends on the chemical composition of the wires and spray parameters of the experiment. The differences of microhardness values at the same specimens under the different loads can be explained in such way: measurements using $100 \mathrm{~g}$ load determinate the properties of one lamella, and measurement with $300 \mathrm{~g}$ load gives results of few lamellas and inclusions of pores or oxides [7].

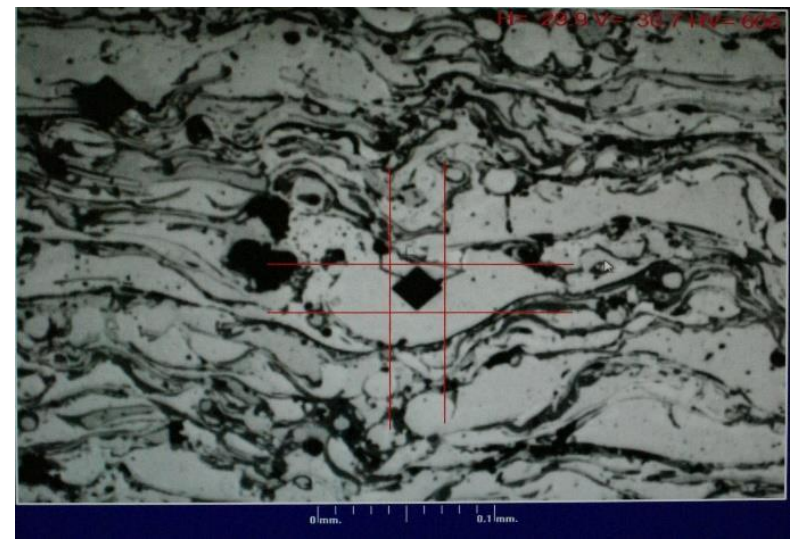

Fig. 3. The marks of Zwick Roel ZHq micro Vickers hardness tester machine

The microstructures of tested coatings are shown in Fig. 4. The pictures of the SEM microscope show the level of porosity, which enables to compare the flattering of the splats with hard particles distribution. It can be seen that for Stein - Mesyfil $932 \mathrm{~V}$ coating the spraying parameters led to a microstructure with low porosity and the coatings have better lamellar structure than STEIN-MESYFIL $954 \mathrm{~V}$ coatings. The higher amount of porosity was measured with Scion Image program in the optical image analysis on cross sections in the STEIN-MESYFIL $954 \mathrm{~V}$ coatings. Porosity was $4.5 \%$. It was the biggest porosity compared in both coatings. The oxide inclusion was $-10.5 \%$. This is typical porosity and oxide inclusions in the thermal sprayed coatings. The oxide content can be traced back to both in flight oxidation of the molten metal particles and surface oxidation of deposited coating layers [7, 12]. Results of the coatings' mechanical properties are given in the Table 3 .

Table 3. Mechanical properties of the coatings

\begin{tabular}{|c|c|c|c|c|}
\hline \multirow{2}{*}{ Coating type } & \multicolumn{2}{|c|}{ Microhardness } & \multirow{2}{*}{$\begin{array}{c}\text { Porosity } \\
\text { level } \\
\pm 0.1, \%\end{array}$} & \multirow{2}{*}{$\begin{array}{c}\text { Oxide } \\
\text { level } \\
\pm 0.1, \%\end{array}$} \\
\hline & $\pm 0,5[\mathrm{HV} 0.1]$ & $\pm 0,5[\mathrm{HV} 0.3]$ & & \\
\hline \multirow{3}{*}{$\begin{array}{l}\text { STEIN - } \\
\text { MESYFIL } \\
932 \mathrm{~V}\end{array}$} & 724 & 556 & 3.5 & 10.9 \\
\hline & 806 & 604 & 1.9 & 5.6 \\
\hline & 836 & 591 & 2.3 & 7.0 \\
\hline \multirow{3}{*}{$\begin{array}{l}\text { STEIN - } \\
\text { MESYFIL } \\
954 \mathrm{~V}\end{array}$} & 714 & 494 & 3.0 & 10.1 \\
\hline & 749 & 505 & 2.7 & 9.1 \\
\hline & 777 & 508 & 4.5 & 10.5 \\
\hline
\end{tabular}

Fig. 5 shows the abrasive wear performance (rubber wheel test) of the thermal sprayed coatings. Among all the coatings from the second spraying experiment had the biggest wear resistance for dry friction in comparison to the coatings from the other spraying experiments.

The wear tracks after Rubber wheel test are shown in Fig. 6. The wear tracks of STEIN-MESYFIL $954 \mathrm{~V}$ coatings are shown in Fig. $6 \mathrm{~b}$ and in these coatings the track of rubber wheel test is much deeper and clearer than in the coatings of STEIN-MESYFIL $932 \mathrm{~V}$. It means that this coating was influenced by dry friction and had the bigger mass loss. The largest mass loss was found at the third spraying experiment. 

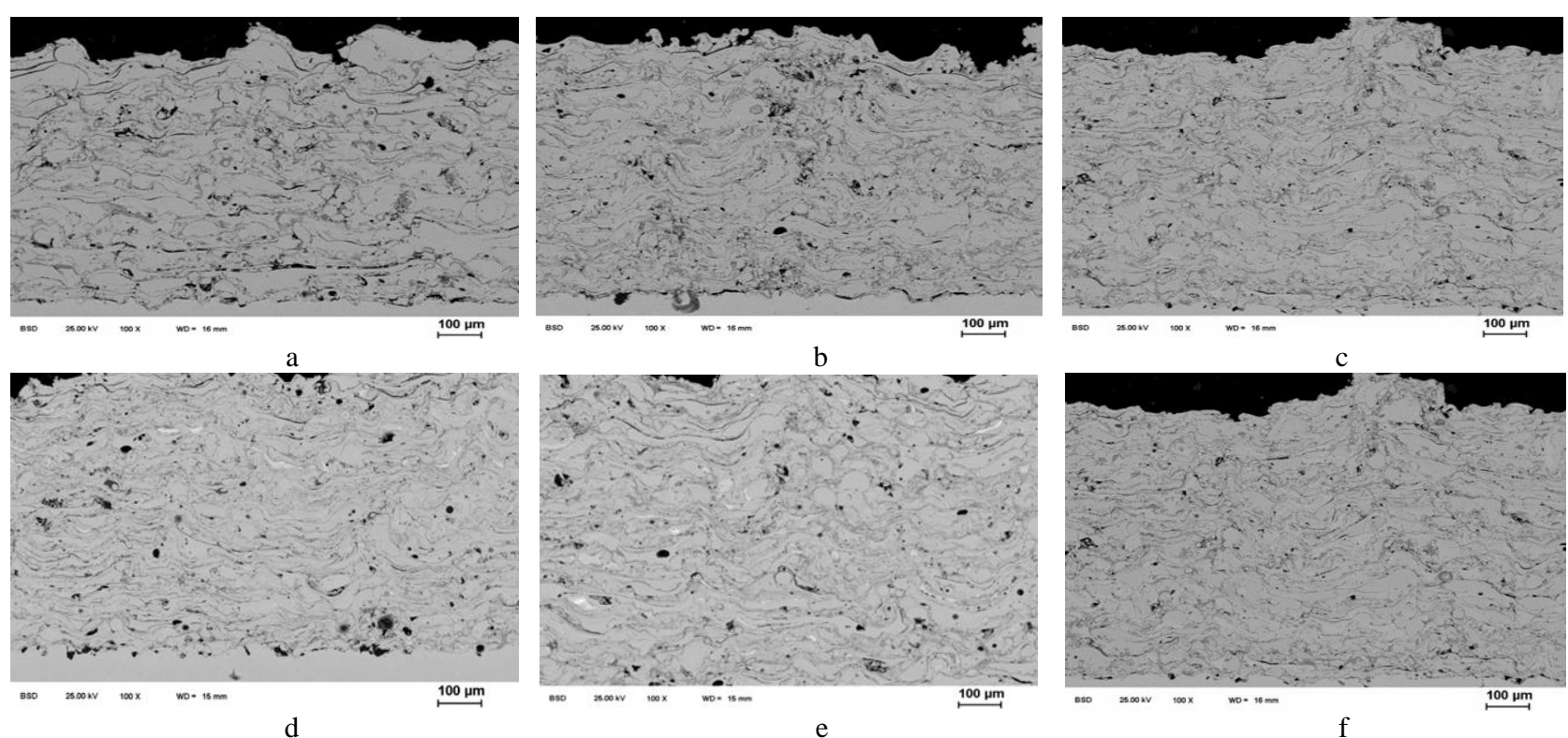

Fig. 4. SEM photographs of cross sections of the thermal spray coatings: a - c STEIN-MESYFIL 932 V; $d-f$ STEIN-MESYFIL 954 V; a, d-320 A - current thermal spray; b, e-350 A - current thermal spray; c, f-380 A - current thermal spray

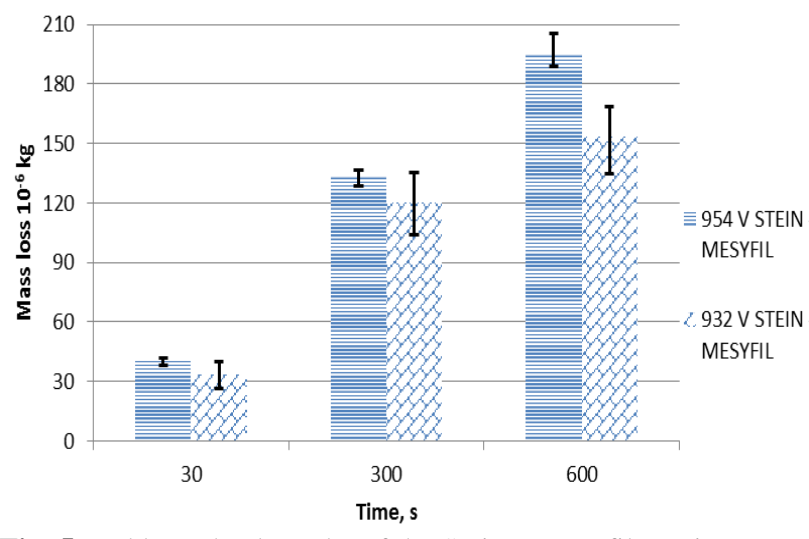

Fig. 5. Rubber wheel results of the Stein - Mesyfil coatings
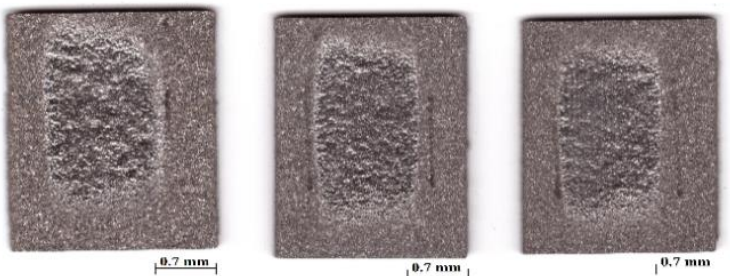

a
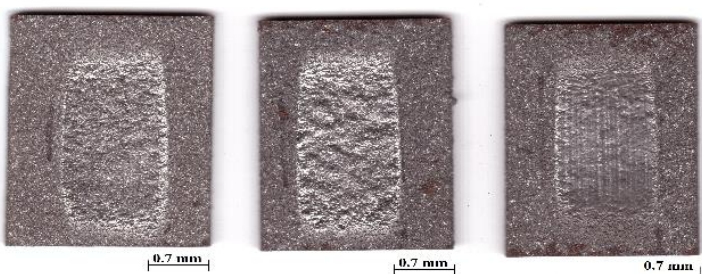

b

Fig. 6. Wear tracks of specimen after dry abrasion test: a-STEINMESYFIL $932 \mathrm{~V}$ coatings on substrate; b-STEIN-MESYFIL $954 \mathrm{~V}$ coatings on substrate

That may exhibit that in the coatings with the highest hardness the residual cracks form. It is possible to conclude that internal stress in the coatings cause the internal cracks and reduces the surface cohesion thus creating the huge mass loss during the dry friction, although the coatings are very hard. In addition, some arc thermal sprayed coatings particle fractures during wear for the STEIN - MESYFIL $932 \mathrm{~V}$ and STEIN - MESYFIL $954 \mathrm{~V}$ coatings due to the relatively larger particle size.

Since super hard particles are intrinsically brittle materials, they would be fractured under a large and localized load during wear.

Relatively smaller particles can lead to the homogenization of the load and thereby to the reduction of particle fractures. It depends on the spraying parameters in the experiment. Probably the bigger spraying current until 350 A formed the smaller spraying particles [1]. As a result, in the second spraying experiment with 350 A current and $36 \mathrm{~V}$ voltage, the coatings were formed with smaller particles and exhibit a higher wear resistance than in the other two experiments.

The resistance measurements from the rubber wheel abrasion test had showed that the results of abrasion test can be directly correlated with the measured coatings' microhardness, porosity and oxide content (Table 3 ). The abrasions wear resistance of the coatings, as evaluated by the Miller test according to ASTM G75 - 95 standard, is presented in the Fig. 7.

The STEIN - MESYFIL coatings showed moderated abrasion wear resistance. The best wear resistance results was given in the second spraying experiment. The biggest mass loss in both coatings was registered in the first and the third spraying experiments. The microstructure of these coatings consists of tightly bounded lamellar structure with considerable porosity. Probably the spraying experiments with low amperage formed bigger lamellar structure [4]. It affects a significant weight loss in the Miller test. The largest particles were removed from the surface in the first test hours and mass loss was the biggest, later the mass loss percentage became normal. The biggest mass loss average after 8 hours was fixed in STEIN-MESYFIL $954 \mathrm{~V}$ coatings, third spraying experiment. It was $615 \times 10^{-6} \mathrm{~kg}$. The mass loss in the STEIN-MESYFIL $932 \mathrm{~V}$ coatings 
(third spraying experiment) was $557 \times 10^{-6} \mathrm{~kg}$. The lowest mass loss average was registered in STEIN-MESYFIL $954 \mathrm{~V}$ coatings (second spraying experiment). It was equal to $547 \times 10^{-6} \mathrm{~kg}$ and $505 \times 10^{-6} \mathrm{~kg}$ in STEIN-MESYFIL $932 \mathrm{~V}$ coatings.

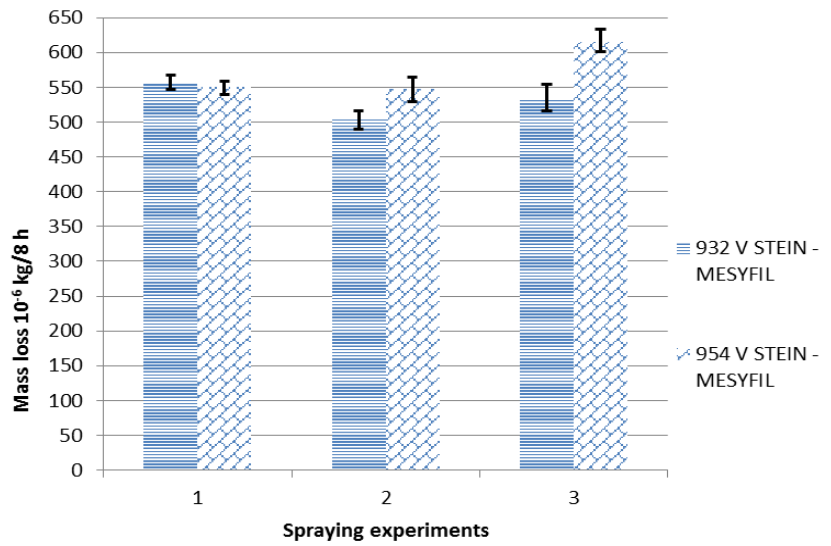

Fig. 7. Miller test results, depending on the coating material and spray parameter set

The mass loss in the STEIN-MESYFIL $932 \mathrm{~V}$ coatings (third spraying experiment) was $557 \times 10^{-6} \mathrm{~kg}$. The lowest mass loss average was registered in STEIN-MESYFIL $954 \mathrm{~V}$ coatings (second spraying experiment). It was equal to $547 \times 10^{-6} \mathrm{~kg}$ and $505 \times 10^{-6} \mathrm{~kg}$ in STEIN-MESYFIL $932 \mathrm{~V}$ coatings.

\section{CONCLUSIONS}

Two different thermal spray coatings with chemical compositions of $\mathrm{Mn}-\mathrm{Si}-\mathrm{Cr}-\mathrm{Mo}-\mathrm{Ni}$ and $\mathrm{Mn}-\mathrm{Si}-\mathrm{Cr}$ wires were sprayed on metal substrate with Castolin - Eutectic EuTronic arc spraying system and a Kemppi Pro 5200 welding machine. The following conclusions can be made:

1. Investigation of coatings' microhardness shows that microhardness of splats (applied load $100 \mathrm{~g}$ ) increases for all coatings with increased amperage. Amplification of amperage produces harder lamellas. Measurements of $300 \mathrm{~g}$ load showed lower values of the results then with $100 \mathrm{~g}$ load, because measurement surface include some lamellas and it is important to pay attention to oxide and porosity number in sprayed coatings.

2. The best results of abrasion were found at the second spraying experiment for all investigated coatings. Mass loss variation in this area was from 0.132 to $0.178 \mathrm{~g}$ per testing cycle (ASTM G65) in STEIN-MESYFIL $932 \mathrm{~V}$ coatings and 0.188 to $0.205 \mathrm{~g}$ per testing cycle in STEIN-MESYFIL 954V coatings. It can be concluded that the Rubber wheel test values are strongly influenced by the surface microhardness and the porosity and oxide inclusions in the coatings. Results showed that the maximum mass loss in coatings was with the maximum quantity of pores and oxides, and the minimum microhardness value (HV0.3) in the coating's (coating $932 \mathrm{~V}$ experiment 1). The largest mass loss in $954 \mathrm{~V}$ experiment 3 coatings was achieved then were the biggest porosity and oxides number, and also the biggest microhardness of coating. Increasing porosity twice mass loss increases twice.

3. The Miller's test results showed mass loss variations in these areas: 500 to $561 \times 10^{-6} \mathrm{~kg}$ per testing cycle (ASTM G75-95) in STEIN-MESYFIL $954 \mathrm{~V}$ coatings and 540 to $634 \times 10^{-6} \mathrm{~kg}$ per testing cycle in STEIN-MESYFIL $954 \mathrm{~V}$ coatings. The lowest and the highest wear values of the studied coatings varied by 1.6 times. This mass loss variation depends on the microstructures lamellas size and oxide inclusions. The measured frictions do not depend on the coatings microhardness.

\section{REFERENCES}

1. Gedzevičius, I., Valiulis, A.V. Analysis of Wire Arc Spraying Process Variables on Coatings Properties Journal of Materials Processing Technology 2006: pp. 206-211.

2. Lugbauer, M. et al. Science, Innovation, and Application, Thermal Spray ASM International 2006: pp. 1345-1350.

3. Stewart, S., Ahmed, R., Itsukaichi, T. Rolling Contact Fatigue of Post-treated WC-NiCrBSi Thermal Spray Coatings Surface \& Coatings Technology 190 2005: pp 171-189.

4. Davis, J.R. Handbook of Thermal Spray Technology. ASM Thermal Spray Society, 2004: pp. 5-232.

5. Gargasas, J., Gedzevičius, I., $\quad$ Valiulis, A.V., Pokhmurska, H., Grund, T., Wielage, B. Wear Behavior and Performance of Coatings Arc Sprayed with Cored Wires Werkstoffe und Werkstofftechnische Anwendungen 50 2013: pp. 374-380.

6. Pawlowski, L. The Science and Engineering of Thermal Spray Coatings. John Wiley \& sons, Ltd, 2007: pp. 79-105.

7. Gargasas, J., Valiulis, A.V., $\quad$ Gedzevičius, I., Pokhmurska, H., Wielage, B., Lampke, T., Rosert, R. The Research of Arc Sprayed Coatings Tribological Properties Proceedings of the International Thermal Spray Conference 2014: pp. $860-865$.

8. Bach, F.W. et al. Modern Surface Technology. Wiley-VCH 2006: pp. $128-136$. http://dx.doi.org/10.1002/3527608818

9. ASTM G65-94 Standard Test Method for Measuring Abrasion Using the Dry Sand/Rubber Wheel Apparatus. Annual Book of ASTM Standards, 03.02, ASTM, Philadelphia, PA, pp. 245-256.

10. Wank, A., Wielage, B., Pokhmurska, H., Friesen, E., Reisel, G. Comparison of Hardmetal and Hard Chromium Coatings under Different Tribological Conditions Surface Coatings and Technologies 201 2006: pp 1975-1980.

11. ASTM G75 - 95 Standart Test Method for Determination of Slurry Abrasivity (Miller Number) and Slurry abresion response of materials (SAR Number).

12. Hamidreze, S.J. Advanced Plasma Spray Applications. Intech 2012: pp. 10-14. 